\title{
Constitución histórica, Constitución escrita y Estado de Derecho
}

\author{
Historical Constitution, Written Constitution and Rule of law
}

\author{
Marco Nicolás Labrín Verdejo* \\ Facultad de Derecho, Universidad de Chile \\ Santiago, Chile \\ «Las constituciones pasan, las instituciones quedan»
}

Bernardino Bravo Lira

RESUMEN: Se indaga en la importancia que revisten las constituciones histórica y escrita en la historia nacional en el marco del desarrollo del Estado de Derecho y establecer los tópicos de relevancia en atención a las instituciones políticas que integran a cada una de ellas, y determinar la relación entre estas instituciones propias de cada Carta y, finalmente, estas en vínculo directo con el Estado de Derecho, comprendidas como un todo que, desde la fundación de Chile hasta nuestros días y a pesar de las grandes crisis sufridas, ha sabido mantenerse en pie.

PALABRAS CLAVE: Estado de Derecho; Constitución histórica; Constitución escrita; instituciones políticas.

ABSTRACT: Is inquired the importance of historical and written constitutions in national history in the framework of the development of the rule of law and establish the topics of relevance in attention to the political institutions that make up each of them, and the relationship between these institutions of each Charter and, finally, these in direct link with the Rule of Law, understood as a whole that, from the founding of Chile to the present day and despite the great crises suffered, he has been able to stand.

KEYWORDS: Rule of Law; Historical Constitution; Written Constitution; political institutions.

\section{INTRODUCCIÓN}

Después de emprender la lectura de la obra de Bernardino Bravo Lira Por la razón o la fuerza: El Estado de Derecho en la Historia de Chile cambió la impresión inicial de ser otro libro de historia porque sus páginas son más que eso a la vez que la explicación que subyace a los acontecimientos importantes del país entendidos los mismos como una cadena de sucesos que han determinado el Chile que conocemos y que se abordan desde

\footnotetext{
* Abogado. Licenciado en Ciencias Jurídicas por la Facultad de Ciencias Sociales de la Universidad Bernardo O’Higgins. Diplomado en Lenguas Clásicas por el Centro de Estudios Griegos, Bizantinos y Neohelénicos, "Fotios Malleros", Facultad de Filosofía y Humanidades de la Universidad de Chile. Alumno y becario del Programa de Doctorado de la Facultad de Derecho de la Universidad de Chile. Ayudante de Investigación Universidad Chile Correo electrónico: marcolabrin15@hotmail.com
} 
una óptica política-filosófica y que repercute en aquella construcción denominada Estado de Derecho.

\section{ALGUNAS NOCIONES SOBRE EL ESTADO DE DERECHO}

El Estado de Derecho, que es el medio en donde las constituciones e instituciones se desenvuelven, CEA EGAÑA lo define como «aquella Nación-Estado o Estado-Sociedad en que impera un sistema jurídico justo, cuya aplicación es objetiva e impersonal, igualmente vinculante para gobernantes y gobernados y en el que, por lo mismo, ninguna arbitrariedad queda ni puede resultar sin sanción. En él, el poder o soberanía se hallan sometidos al Derecho» 1 .

Sostiene VIVANCo MARTíneZ que el origen del Estado de Derecho se halla a mediados del siglo XIX como un intento de evitar los abusos de poder del absolutismo ${ }^{2}$, el que se caracteriza por ausencia de las libertades, concentración del poder en una sola persona -el rey- y falta de limitaciones a la responsabilidad de quien ejerce la autoridad. Para BRAVO LIRA el Estado de Derecho no es una invención del siglo $\mathrm{XIX}^{3}$ y tiene su origen en Europa en la Edad Media y en América al comienzo de la Edad Moderna ${ }^{4}$, coincidiendo con los grandes descubrimientos geográficos de expediciones al servicio de las coronas portuguesa y española.

Nogueira AlCAlÁ y Cumplido CERECEDA -citando a Platón y Aristóteles- estiman que los antecedentes del Estado de Derecho se remontan a la Grecia clásica ${ }^{5}$ pero, en realidad, en la Edad Media se perfila la idea de la racionalidad de la ley frente al carácter despótico del monarca, atendiendo a la justicia y el bien común, y, mientras que la juridicidad comienza a delimitar los alcances del poder del Estado, explicitan Locke y Montesquieu la teoría de la separación de los poderes ${ }^{6}$, sobre todo el último a través de su obra De l'esprit des lois.

Para MONTESQUIEU era preocupante que el poder se concentrara en un solo individuo y detalló sus consecuencias: «Cuando el poder legislativo está unido al poder ejecutivo en la misma persona o en el mismo cuerpo, no hay libertad porque se puede temer que el monarca o el Senado promulguen leyes tiránicas para hacerlas cumplir tiránicamente. Tampoco hay libertad si el poder judicial no está separado del legislativo ni del ejecutivo. Si va unido al poder legislativo, el poder sobre la vida y la libertad de los ciudadanos sería arbitrario, pues el juez sería al mismo tiempo legislador. Si va unido al poder ejecutivo, el juez podría tener la fuerza de un opresor. Todo estaría perdido si el mismo hombre, el mismo cuerpo de personas principales, de los nobles o del pueblo, ejerciera los tres poderes: el de hacer las leyes, el de ejecutar las resoluciones públicas y el de juzgar los delitos o las diferencias entre particulares» ${ }^{7}$.

${ }^{1}$ CEA Egaña (2008) p. 238.

${ }^{2}$ VIVANCO MARTíNEZ (2001) p. 231.

${ }^{3}$ Bravo LiRA (1996) p. 22.

${ }^{4}$ BRAVO LiRA (1996) p. 67.

${ }^{5}$ Nogueira Alcalá y Cumpldo Cereceda (2001) p. 213.

${ }^{6}$ Nogueira Alcalá y Cumplido Cereceda (2001) p. 214.

${ }^{7}$ MontesQuieu (2003) pp. 206-207. 
En el transcurso del siglo XVII se encuentran los elementos que caracterizan este pensamiento, tales como la exaltación de la razón humana, la crítica y revisión de los autores clásicos, la existencia de Dios demostrada a través de la razón, el carácter científico que permite entender la naturaleza y la idea de que el hombre nace bueno pero es la sociedad la que le corrompe, y es en este ambiente intelectual que el Estado monárquico es influenciado y no obedece ya a los caprichos del rey sino que responde a fines como el desarrollo de la sociedad y la felicidad pública, dicho de otra manera, a saber guiar el «buen gobierno», ampliando con esto sus facultades y ejerciéndolas por medios de las oficinas, reemplazando a los antiguos oficiales ${ }^{8}$.

Teniendo lo anterior presente se comprende mejor la aseveración de BRAVO LIRA y por qué el Estado de Derecho no es una creación moderna, aceptando que el término surge en la ciencia jurídica alemana con Robert von Mohl usando la expresión rechtsstaat y entendiéndolo desde una visión individualista ${ }^{9}$. Sin embargo, esta interpretación del concepto alemán corresponde a una de las muchas que existen ${ }^{10}$ y que, además, han variado su significación. El Estado de Derecho sería más bien una «realización histórica», porque se desprende del pensamiento de cada pueblo y época, haciendo de esta una realidad múltiple y cambiante ${ }^{11}$.

Son elementos esenciales del Estado de Derecho los siguientes $^{12}$ : 1 - El imperio de la ley. Surge como un mecanismo de control en el que se crea una ley de carácter general, abstracta y permanente, racional y emanada del órgano constituido válidamente para su dictación, y cuya autoridad se extiende a gobernantes y gobernados, distinto a lo que ocurría con el rey absoluto, cuyos poderes no estaban bajo las limitaciones de las leyes. Esta ley, en cuanto autoridad, es ley fundamental a la que se someten todas las demás. 2- $\boldsymbol{E} \boldsymbol{l}$ dogma de la división de poderes. Sobre este punto no es necesario dar más detalles que los ya indicados y agregar solo que este principio es un dogma fundamental para el constitucionalismo clásico. 3- La legalidad de la Administración. Su origen se encuentra en la ausencia de limitaciones a los poderes del rey frente a sus súbditos, pero bajo este principio los daños y perjuicios que ocasione la Administración a las personas por infracción de ley generan responsabilidad y sanciones. 4- El control y la responsabilidad de los gobernantes. Este principio postula que los actos de la Administración, del nivel que sea, pueden ser criticados por la ciudadanía y deben ser públicos e informados porque lo contrario dañaría el Estado de Derecho debido a que los ciudadanos no podrían ejercer su facultad de controlar a sus gobernantes. Este incumplimiento acarrea responsabilidad para la Administración y, eventualmente, sanciones al que provocó los perjuicios o daños. 5- $\boldsymbol{E} \boldsymbol{I}$ principio de la jerarquía de las normas. Este principio, desarrollado principalmente por Hans KELSEN ${ }^{13}$, importa que las leyes poseen rango y uno de validez, encontrándose en la

\footnotetext{
${ }^{8}$ BRAVO LiRA (1986a) p. 104.

${ }^{9}$ ViVANCO MARTÍNEZ (2001) p. 231.

${ }^{10}$ Vivanco MartíneZ (2001) pp. 232-235 desglosa brevemente las diversas visiones que existen sobre el Estado de Derecho (acá se señala solo una).

${ }^{11}$ Bravo LiRA (1996) p. 22.

${ }^{12}$ Nogueira Alcalá y Cumplido Cereceda (2001) pp. 220-224.

${ }^{13}$ KELSEN (2009) presenta su teoría del derecho positivo como una jerarquía de leyes, que parte desde una norma básica en la que todas las demás normas están relacionadas entre sí, ya sea como normas inferiores, cuando se compara una con la otra, o como normas superiores.
} 
cúspide la Constitución y bajo ella todas las demás normas jurídicas. 6- El principio de la supremacía de la Constitución y la jurisdicción constitucional. Estos principios, las más relevantes bases de la teoría constitucional, significan, respectivamente, que la Constitución jerárquicamente se sitúa en la cima del ordenamiento legal y es la Ley Suprema del Estado y fundamento del sistema jurídico, y existen órganos que realizan un control de la vigencia de la supremacía de la norma fundamental.

\section{BREVE NOTICIA ACERCA DEL ESTUDIO DE LAS CONSTITUCIONES EN LA ANTIGÜEDAD}

Autores clásicos como ARISTÓTELES y CICERÓN trataron sobre la constitución y es evidente que su concepción no es la misma que se tiene hoy de ella. Así, para GuZMÁn BRITO, pudiendo solo ahora unificarse bajo una sola terminología la variedad de conceptos que por la diferencia de idiomas y culturas en un sentido amplio existen, la constitución se concibe como «las reglas de sobre designación de los titulares del poder político de la sociedad, y sobre la organización y distribución, competencias y gestión de este poder» ${ }^{14}$.

ARISTÓTELES ofrece uno de los primeros acercamientos al concepto de constitución,

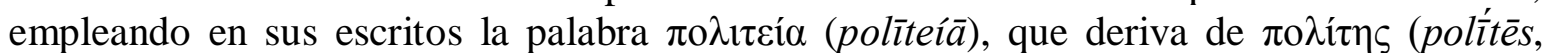
«ciudadano»), la que proviene de $\pi$ ó $\lambda$ เৎ (pólis, «ciudad estado»), y aunque consta de muchos significados que hacen difícil precisar su sentido original puede entenderse como «constitución de un Estado» en un sentido genérico y que podría aplicarse a cualquier clase de organización política, pero se infiere de la lectura de las obras políticas del filósofo que la expresión constitución es sinónimo de «régimen de gobierno» al referir las que son las mejores constituciones y sus equivalentes corruptos y, en este sentido, GUZMÁN BRITO afirma que el autor uso el término de modo restringido para aludir a la forma correcta del gobierno de todos o de la mayoría, en oposición a la $\delta \eta \mu \kappa \rho \alpha \tau i ́ \alpha$ (dēmokratíā), y se valió de la misma palabra para definir la mezcla entre la oligarquía y la democracia, la que para el pensador griego sería la mejor forma de gobierno.

En la Política se dice que «Un régimen político es una ordenación de las diversas magistraturas de la ciudad y especialmente de la que tiene el poder soberano» ${ }^{15} \mathrm{y}$ «un régimen político es una organización de las magistraturas en las ciudades, cómo están distribuidas, cuál es el órgano soberano del régimen y cuál es el fin de cada comunidad» ${ }^{16}$ y de esto puede provenir la confusión que existe al interpretar la palabra constitución, dado que el Estagirita define régimen político, no constitución, pero -mencionado antes- se las puede entender sinónimos.

Igual sucede con POLIBIO porque en el libro VI de sus Historias en relación a la constitución de Roma -la cual concibe como Aristóteles ya que su intención es explicar las causas por las que Roma alcanzó la hegemonía- señala que «[...] lo más útil para los lectores en su dedicación sería comprender y profundizar cómo pudo suceder y cuál fue la

\footnotetext{
${ }^{14}$ GUZMÁN BRITO (2002) p. 2.

${ }^{15}$ ARISTÓTELES (2007) III 6, 1, $1278 \mathrm{~b} 8$ ss.

${ }^{16}$ ARISTÓTELES (2007) IV 1, 10, 1289a15 ss.
} 
constitución que lo consiguió, que los romanos llegaran a dominar casi todo el mundo en menos de cincuenta y tres años, cosa que no tiene precedentes» ${ }^{17}$.

La concepción romana de constitución, tal como en Grecia, no se corresponde con un cuerpo normativo y sería una creación moral fundada en la tradición del pueblo romano, la costumbre de los antepasados y unas pocas leyes emanadas del Senado. Un ejemplo se ve a través de los principios y normas de derecho natural que, aunque no escrituradas, estaban arraigadas en la conciencia de los ciudadanos y contribuían fuertemente a crear constitución.

La forma de mentar este «ente» enlaza con dos palabras que CICERÓN usa para aludir a constitución, constitutio, que concierne directa o indirectamente al régimen político mixto entendido como la combinación armoniosa de los tres regímenes llamados rectos ${ }^{18}$, aunque GUZMÁN BRITO aclara que esta voz latina no atañe a la constitución política sino a un conjunto $^{19}$, al conjunto de regímenes políticos que el autor romano trata en sus obras, y status, que no se traduce como constitución o forma de gobierno porque describe una forma de ser de este, lo que se refleja en el pasaje «Atqui, si quaeres, ego quid expectem, quoniam scriptum est a te de optimo rei publicae statu, consequens esse uidetur ut scribas tu idem de legibus $[\ldots]{ }^{20}$. Retóricamente constitutio y status son sinónimos y -siguiendo a GUZMÁN BRITO- la primera es interpretable como constitución ya que no se altera el sentido que CICERÓn le dio en sus obras.

\section{LAS CONSTITUCIONES Y LAS INSTITUCIONES POLÍTICAS}

Las instituciones políticas examinadas, enmarcadas dentro de uno u otro grupo y que están representados por las constituciones histórica y escrita, en Chile comienzan a convivir a partir del constitucionalismo.

BRAVO LIRA habla de la constitución histórica ${ }^{21}$ pero esta expresión acá es sinónima de constitución consuetudinaria, «aquella que se forma a partir de la lenta evolución de las instituciones de Estado y de prácticas constantes consagradas por el uso y la tradición histórica» $^{22}$, y constitución escrita es «aquella que se concreta en uno o más textos promulgados por un procedimiento valido, y que por su precisión y fijeza constituyen una garantía para gobernantes y gobernados ${ }^{23}$.

\footnotetext{
${ }^{17}$ Polibio (1981) VI, 1, 3.

${ }^{18}$ CiCERón (1984) habla de tres regímenes o clases de gobierno, a los que llama rectos, Monarquía, en que el poder está en manos de una sola persona, Aristocracia, en que el poder está en manos de un grupo selecto de individuos, y Democracia, en que el poder está en manos del pueblo. A su vez, el orador distingue un cuarto régimen que combina los tres modelos antes señalados, rescatando lo mejor de cada uno.

${ }^{19}$ GUZMÁN BRITO (2002) p. 29.

${ }^{20}$ CiCERón (1984) I, 5, 15 (la traducción es «Pues si me preguntas qué es lo que yo espero, es que, puesto que tú has escrito sobre la forma ideal del estado, parece consecuente que tú también escribas sobre las leyes $[\ldots] \gg)$.

${ }^{21}$ En lo sucesivo, se dirá constitución histórica acorde la nomenclatura de BRAVO LIRA.

${ }^{22}$ Vivanco MartíneZ (2001) p. 384.

${ }^{23}$ ViVAnCO MARTíneZ (2001) pp. 383-384.
} 
Las instituciones, término proveniente del latín institutio y que significa «fundamento»o «cimiento», es creación del hombre en oposición a aquellas que son naturales y que apuntan a dar satisfacción a necesidades humanas sociales, son entes colectivos que gozan de estabilidad. VERDUGO MARINKOVIC y GARCíA BARZELATTO definen las instituciones como «creaciones del obrar humano colectivo que, con carácter de permanencia, procuran satisfacer necesidades sociales éticas» ${ }^{24}$.

VIVANCO MARTÍNEZ - citando a Hauriou- expresa que el Estado es la institución de las instituciones y por tanto las demás están por debajo de él, entre ellas las mismas constituciones $^{25}$. Hay instituciones jurídicas y políticas, esto es y en ese orden, «aquellas organizaciones que están reguladas por normas jurídicas y corresponden a la estabilización de normas jurídicas de convivencia» y «aquella destinada al poder, su legitimación o ejercicio, siendo estas las que permiten la interacción entre la realidad, las ideas contingentes y la necesidad de contar con una adecuada estabilidad del sistema», y puede colegirse que pueden ser compatibles, v. gr., la judicatura es una institución política y jurídica porque la disciplina el Derecho.

En opinión de VIVANCO MARTínEZ, las instituciones responden a una necesidad de la sociedad como elemento de existencia del Estado, llamado población ${ }^{26}$ o elemento humano $^{27}$, y aquél, independiente de su denominación, determina cómo o qué fuerza tiene cada institución, las que buscan la estabilización del poder y permitiendo que sus ideales se expresen a través de ellas, cual aconteció con el Parlamento, en el que los representantes profieren el pensamiento del pueblo, teniendo un desempeño relevante durante el Parlamentarismo y que presentó ya sus primeros indicios de diversidad en el periodo conservador, lo que EDWARDS VIVES refiere como «dentro de la cámara había ya partidos» ${ }^{28}$, aludiendo a la pronta venida de lo que serían los Partidos Políticos y el «gobierno de partidos» que predica BRAVO LIRA.

Agregan Verdugo MARINKOVIC y GARcía BARZELATTO que las instituciones duran menos o más tiempo en cuanto respondan mejor o peor a las necesidades del medio social, y según que esas ideas interpreten o no el sistema de valores que esté vigente en el medio $\operatorname{social}^{29}$, y las instituciones políticas tienen que vincularse con el poder central (v. $g r$. , Presidente, Parlamento, Partidos Políticos).

Las instituciones políticas se clasifican en uno de los dos grupos enunciados, y pertenecen al primero, a la constitución histórica, el Presidente, la Judicatura y las Fuerzas Armadas, y en el segundo, en la constitución escrita, se hallan el Parlamento y los Partidos Políticos. Sobre este distingo, señala BRAVO LIRA que las primeras son también el núcleo básico del Estado y pilares de la constitución histórica y las segundas instituciones mucho más

\footnotetext{
${ }^{24}$ Verdugo Marinkovic y García Barzelatto (2010) p. 25.

${ }^{25}$ VIVANCO MARTÍNEZ (2001) p. 68.

${ }^{26}$ Nogueira AlCAlá y Cumplido Cereceda (2001) p. 66.

${ }^{27}$ ViVANCO MARTíNEZ (2001) p. 179.

${ }^{28}$ EDWARDS ViVES (2012) p. 86.

${ }^{29}$ Verdugo Marinkovic y García Barzelatto (2010) p. 29.
} 
recientes y vinculadas al modo de gobernar ya que las instituciones de la constitución histórica tienen su origen en la temprana Edad Moderna ${ }^{30}$.

Otro aspecto a considerar es que en Chile, muy distinto al resto de América, muchos de los problemas suscitados en Europa y que más tarde llegaron a los reinos de Indias no pudieron ser resueltos por los mismos medios obligando a las instituciones a evolucionar para responder a las situaciones que acontecían en el naciente país, por ende el estudio de estas instituciones no es estático en el tiempo sino progresivo a causa de sus funciones verse alteradas en los respectivos periodos históricos y en los cuales cada institución tiene mayor o menos preeminencia sobre las otras.

En lo sucesivo, expongo las instituciones en particular y sus principales atributos en cada uno de los momentos del Estado de Derecho.

\section{El Presidente}

Es quizás el personaje más importante y primero de las instituciones de la constitución histórica porque su origen está ligado a la fundación de la ciudad de Santiago y él se relaciona con todas las demás instituciones ${ }^{31}$.

Tras asentarse en Chile, Pedro de Valdivia fue nombrado como el primer Gobernador y Capitán General del Reino ${ }^{32}$, cargo que se traducía en representar al rey y ejecutar sus decisiones $^{33}$. La autoridad del Gobernador, Capitán General del Ejército y Presidente de la Real Audiencia estaban unidas y encarnadas en una sola persona ${ }^{34}$. BRAVO LIRA se refiere al Gobernador y al Presidente de manera indistinta pero existen diferencias ya que el primer Presidente de la República es Manuel Blanco Encalada en 1826, si bien fue llamado así desde que se instauró la Real Audiencia en Chile.

Chile se estableció como una gobernación en lo político y capitanía general en lo militar, situación que se mantendría a partir de Pedro de Valdivia, transmitiendo sus cargos de forma inalterable hasta $1816^{35}$. En esta época, el Gobernador tenía esta triple identidad que le confería diversos poderes ${ }^{36}$, esto es, encabezaba la Administración y dirigía el gobierno en el territorio del reino, como Capitán General comandaba los ejércitos que, aunque no permanentes inicialmente, luego de la perdida de las ciudades del sur en 1598 se estableció en las fronteras fijadas tras el levantamiento araucano en el Biobío ${ }^{37}$, y en su calidad de Presidente de la Real Audiencia la dirigía teniendo a su cargo la vigilancia general del Poder Judicial.

\footnotetext{
${ }^{30}$ BRAVO LIRA (1996) p. 25.

${ }^{31}$ BRAVO LIRA (1994-1995) pp. 147-148 y (1996) p. 26: «[...] entre los actores políticos, el Presidente ocupa un lugar privilegiado».

32 BRAVO LiRA (1986a) p. 82.

${ }^{33}$ CAMPOS HARRIET (1999) p. 45.

${ }^{34}$ BRAVO LIRA (1994-1995) p. 156.

${ }^{35}$ BRAVO LiRA (1986a) p. 85.

${ }^{36}$ Villalobos Rivera et al. (2006) p. 136.

${ }^{37}$ CAMPos Harriet (1999) p. 52.
} 
Con el ingreso de las ideas ilustradas, el Presidente de la Real Audiencia pasó a ser un cargo honorífico y cesa así el vínculo entre la Administración y la Judicatura, lo mismo pasó en el resto de América, y por dicho cese el Gobernador no participa en decisiones de la jurisdicción, la que se vuelve independiente, y la Real Audiencia pierde competencia en asuntos de gobierno y hacienda.

Después de la independencia de Chile y desaparecida la figura del Gobernador, la institución del Presidente se debilitó de tal manera que ya no representaba la autoridad necesaria para poner orden en el país, y en este lapso tuvo lugar la llamada Anarquía, situación que terminó por obra de Diego Portales, quien intervino a favor del Presidente devolviéndole su autoridad como si se tratase de un rey, aunque su fuerza radica en las atribuciones que se le otorgaron como cabeza de la Administración. Este resurgimiento de la autoridad en el Presidente es propio del Periodo Conservador, que se extendió entre 1831 y 1861.

Con posterioridad a la llegada de los Partidos Políticos y su auge bajo el Periodo Parlamentario, entre 1891 y 1925, el Presidente vio otra vez disminuido su poder. En efecto, el 5 de septiembre de 1924 un grupo de oficiales constituye lo que se llamó Comité Militar y va al Palacio La Moneda presentándole al Presidente Arturo Alessandri Palma una serie de peticiones relativas al despacho de proyectos de ley pendientes, el gobernante se compromete a buscar solución si vuelven a los cuarteles, se formó un nuevo gabinete y la Cámara de Diputados y el Senado el 8 de septiembre votó los proyectos pendientes, mas el Comité Militar decide seguir funcionando y solicita disolver el Congreso al Presidente quien renunció al cargo exiliándose en Argentina y de ahí, junto con su esposa, se va a Europa, donde permanece hasta 1925, y en enero de este año una nueva junta le pide regresar y asumir el mando para restablecer la normalidad institucional volviendo finalmente el dimitido en marzo abocándose a modificar el régimen político y redactar una nueva Constitución, y renace, entonces, el presidencialismo, contrapartida de las agrupaciones políticas, compensando su prestigio con el poder que le había sido arrebatado, solo que inicia un nuevo rol porque, aunque recobró sus facultades y se transformó en una figura negociadora, acabó por convertirse en subordinado de los partidos que le habían elegido, siendo un mero ejecutor de sus proyectos, y este modelo finalizó con el alzamiento de las Fuerzas Armadas el 11 de septiembre de 1973 contra Salvador Allende, derribando a los partidos con él.

\section{La Judicatura}

Es la segunda institución propia de la constitución histórica y su fundamento se halla tempranamente en la institución de la Real Audiencia, tribunal de la corte en que el rey delegaba su facultad de administrar justicia ${ }^{38}$.

La Real Audiencia tuvo en las Indias una competencia mucho mayor que en España ${ }^{39}$, se instauró en Chile en Concepción funcionando entre 1567 y 1575 y se restableció en Santiago el 8 de septiembre de 1609 estando en actividad por más de dos siglos, en 1811,

\footnotetext{
${ }^{38}$ CAMPOS HARriet (1999) p. 45.

${ }^{39}$ BRAVO LiRA (1996) p. 45.
} 
con el gobierno en manos de una Junta Gubernativa, se ejerció una serie de presiones sobre sus ministros siendo acusados de instigar el motín de Tomás de Figueroa el 1 de abril contra la Junta por lo que algunos oidores renunciaron, José Santiago de Aldunate y Guerrero el 6 de abril y Félix Francisco Bazo y Berry y Manuel de Irigoyen el 9 de abril, quedando solo el regente Juan Rodríguez Ballesteros y el decano José de Santiago Concha ya que la fiscalía había vacado el 6 de abril por muerte del titular, el barón de Juras Reales, y el gobierno, estimando que son contrarios a la justa causa del Reyno de conservar estos dominios al soberano Fernando VII, ordenó que en tres días, a contar del 24 de abril, se retirara el regente a la ciudad de San Fernando y el decano a La Ligua, con goce de pensión mensual de 150 pesos, y se produjo el cese del tribunal ${ }^{40}$.

Vencidas las tropas chilenas el 2 de octubre de 1814 en Rancagua iniciándose el período de Reconquista española, el gobernador y capitán general Mariano Osorio reinstaló con los antiguos ministros que seguían en Chile (Santiago Concha y Aldunate y Guerrero) la Real Audiencia, la cual aquellos reabrieron solemnemente el 15 de marzo de 1815 siendo presidida por el mismo Osorio, y llegó a su fin definitivamente el 13 de febrero de 1817 por huir los Ministros a Valparaíso sabedores de la derrota de las armas reales el día antes en la batalla de Chacabuco ${ }^{41}$ y con la que se extinguió el dominio de España en Chile.

La Real Audiencia, como supremo tribunal del reino, tiene el mismo tratamiento que el rey y su rol es proteger a los gobernados frente a los actos del gobierno, administrar justicia en materias civil y criminal, y servir de órgano consultivo al Presidente en materia política ${ }^{42}$. En 1776 se dictó la instrucción de regentes y aplicó en Chile el año siguiente designando al regente $^{43}$ autoridad que preside la Real Audiencia, dejando al Gobernador de lado, con un título simbólico, pues ya no participa de las decisiones jurisdiccionales ${ }^{44}$.

Con la llegada del constitucionalismo en tiempos de la independencia, la Judicatura se nominó Poder Judicial, al separarse de la Administración y ser catalogada como otro de los poderes del Estado, y se supeditó a una norma estricta que la regula e igual ocurrió con el presidente y el Parlamento ${ }^{45}$. La Real Audiencia transformada en Corte de Apelaciones en 1817 perdió sus competencias y fue relegada en relación a las demás instituciones.

La Judicatura en 1823 se estructura como actualmente se le conoce, ampliándose su jurisdicción, y con las constituciones de 1925 y 1980 tiene rango constitucional, subsistiendo previamente sin necesidad de tal reconocimiento en la carta fundamental, y comparte la misma condición que el Presidente en cuanto perduró mientras las constituciones se sucedían unas a otras.

\section{Las Fuerzas Armadas}

\footnotetext{
${ }^{40}$ BARRIENTOS GRANDON (2000) p. 51.

${ }^{41}$ Ibíd.

42 Villalobos Rivera et al. (2006) p. 137 y Frías VAlenZUela (2007) p. 54.

${ }^{43}$ EyZAGUIRRE GUTIÉRREZ (1967) p. 25.

${ }^{44}$ BRAVO LIRA (1986a) p. 132.

${ }^{45}$ BRAVO LIRA (1996) p. 33.
} 
La última institución perteneciente a la constitución histórica son las Fuerzas Armadas, carente de trato en la doctrina con profundidad suficiente ${ }^{46}$, su rasgo distintivo es que de simple mecanismo de defensa para el reino pasó a ser una efectiva garantía de la protección de la institucionalidad $\mathrm{y}$, pese a tratarse de una organización muy antigua, sus características han cambiado conforme a la época y lugar en que se han desarrollado ${ }^{47}$.

Son de carácter gubernamental el gobierno, la justicia, la hacienda y la guerra. Las Fuerzas Armadas tuvieron particular relevancia por la necesidad en Chile de proteger las fronteras del sur, y tras el levantamiento indígena de 1598 el Gobernador-Capitán General -llamado aquí Presidente militar, distinto del Presidente gobernante que le seguiría en los años sucesivos $^{48}$ - asumió el mando del ejército, el cual en 1601 Alonso de Ribera y Zambrano propuso a Felipe III que fuera permanente.

El ejército aumentó sus dotaciones y es uno de los primeros en el mundo en hacerlo, su función estaba guiada por el Gobernador atendiendo a la guerra y no a la Administración y con la llegada de la Ilustración y el constitucionalismo los gobiernos castrenses se hicieron cada vez más recurrentes $\mathrm{y}$, si no eran tales, los alzamientos propios de la Anarquía posterior a la independencia, coincidiendo con la decadencia de la monarquía española, pero este fenómeno del «militarismo»-desconocido hasta ese momento- fue silenciado por la obra de Portales restaurando la autoridad y respeto al gobernante civil que se había perdido $^{49}$ y estaba lejos de ser erradicado porque con las crisis de 1924 despertó de su letargo y derribó el orden imperante que se había mantenido sólido desde 1830. BRAVO LIRA sostiene que las Fuerzas Armadas asumen un rol protagónico en cuanto que la Administración se vuelve inoperante, tomando las primeras cartas en el asunto con tal de restaurar el orden ${ }^{50}$.

Bajo una innegable crisis, por ejemplo, el 23 de agosto de 1973 la Cámara de Diputados aprobó el «Acuerdo sobre el grave quebrantamiento del orden legal y constitucional de la República» acusando al Gobierno de incurrir en violaciones tales como aplicar medidas de control económico y político para luego instaurar un sistema totalitario, vulnerar garantías constitucionales, dirigir una campaña de difamación contra la Corte Suprema, afectar la libertad de expresión, reprimir con violencia a los opositores e intentar infiltrar políticamente a las Fuerzas Armadas, éstas (y Carabineros) el 11 de septiembre de 1973 se atribuyen el rol de resguardar la institucionalidad frente a los excesos del gobierno de partido y derrocan al Presidente Salvador Allende, clausuran el Parlamento y resuelven la disolución de los Partidos Políticos. Para Bravo Lira, teniendo presente, como en un

\footnotetext{
${ }^{46}$ BRAVO LiRA (1996) p. 172.

${ }^{47}$ Verdugo MarinKovic y García Barzelatto (2011) p. 63.

${ }^{48}$ BRAVO LIRA (1996) p. 177.

49 BRAVO LiRA (1992) p. 188 dice que Portales consolidó el orden interno del país al restablecer la subordinación del ejército al gobierno, a la figura del Presidente.

50 Verdugo Marinkovic y García BARzelatto (2011) p. 63 manifiestan que «Desde los orígenes del constitucionalismo clásico se les ha asignado a las FF.AA. una función auxiliar de los gobernantes, subordinándolas jerárquicamente al poder civil, como instrumento que cumple uno de los fines de la organización estatal».
} 
principio con el Gobernador, si non facias no eris, la patria no se puede poner en riesgo bajo ninguna circunstancia, deponiendo al tirano ${ }^{51}$.

Las Fuerzas Armadas, parte del núcleo del Estado y de la constitución histórica, se erigen garantes de la institucionalidad en situaciones excepcionales de vacíos de poder bajo gobiernos civiles y su relación con el Estado de Derecho es estrecha y duradera por cuatrocientos años.

\section{El Parlamento}

El Parlamento, pese a su adopción reciente, ocupa un papel relevante como representante de la constitución escrita, la que lo incorpora y regula. En América jamás se vio algo así ya que es una institución eminentemente europea. En Chile comprende los años 1831 a 1973, y sus funciones se reducen a legislar y fiscalizar ${ }^{52}$. El denominado Congreso de 1811 no fue una institución permanente y le sucedieron otros en 1823, 1824, 1826 y 1828 y la transitoriedad de ellos se condice con las variadas constituciones o intentos, mejor dicho, que caracterizaron de este periodo y recién en 1831, bajo la figura fuerte de Portales, el Parlamento se asentó institucionalmente. BrAvo LIRA destaca que el caso de Chile fue particular porque el Parlamento sesionó ininterrumpidamente noventa y tres años hasta el año 1924 y colapsó después en 1932 y en $1973^{53}$.

Otro punto a resaltar son las etapas que distingue BRAVO LIRA en la historia del Parlamento, una de establecimiento y consolidación seguida por una de auge bajo la influencia de los partidos y el surgimiento del Parlamentarismo en Chile, siendo al principio eje del gobierno y luego oposición al Presidente, al servicio de las oligarquías partidistas y, finalmente y tras las crisis, a lo que se suma la decadencia de los Partidos Políticos, se halla un Parlamento con miembros de partido que carecen del poder que tuvieron antaño ${ }^{54}$.

\section{Los Partidos Políticos}

Los Partidos Políticos son una institución de origen todavía más reciente que el Parlamento y se vincula estrechamente con él, emergen bajo su amparo y le deben el apogeo que tuvieron con posterioridad, alcanzando una singular importancia en materia política ${ }^{55}$.

No existe en la Constitución una definición de esta institución, para NoGUEIRA ALCALÁ «un partido político es una asociación voluntaria y permanente de ciudadanos que sustentando unos mismos principios o concepción sobre el quehacer social, participan activamente en la formación de la voluntad política estatal y buscar acceder al poder gubernamental a través del apoyo popular obtenido para sus candidatos en elecciones

\footnotetext{
${ }^{51}$ BRAVO LIRA (1996) pp. 220-221.

52 BRAVO LIRA (1996) p. 45.

${ }^{53}$ BRAVO LIRA (1992-1993) pp. 305-306 y (1996) p. 46 expone que «En su tiempo fue uno de los parlamentos más antiguos y estables del mundo. En Europa sólo le superaba el inglés y fuera de Europa, el estadounidense».

${ }^{54}$ BRAVO LIRA (1996) p. 47.

55 Verdugo Marinkovic y García BARZElatto (2011) pp. 46-47.
} 
competitivas y en su participación en decisiones que adopten directamente los ciudadanos en referéndum o plebiscitos, fortaleciendo el sistema democrático de gobierno» ${ }^{56}$.

Los partidos en Chile tuvieron un considerable arraigo, BRAVO LIRA señala que gozaron de particular suerte pues son contados los casos en Europa en que prosperaron, comenzaron ya en el gobierno del presidente José Joaquín Pérez su influencia y esta se extendió hasta la caída del gobierno de Salvador Allende el 11 de septiembre de 1973 mediante un alzamiento militar (Ejército, Armada, Fuerza Aérea y Carabineros) que justamente dispuso, entre sus primeras medidas y al tercer día del pronunciamiento, la clausura del Congreso Nacional y declaró vacantes los cargos de los parlamentarios que entonces invisten esa calidad (Bando $\mathrm{N}^{\circ} 29$ ).

Tal como acontece con el Parlamento, la existencia de los partidos se divide en etapas similares a las descritas, primero una en que gobiernan en conjunto con el Presidente reconociendo su autoridad y otra ulterior en la que se hacen con un poder tal que aquél, la Judicatura y las Fuerzas Armadas se ven anulados, perdiendo sus poderes frente al Parlamento cuyos integrantes estaban bajo las órdenes de los líderes partidistas, quienes además determinaban el sucesor del Presidente. La etapa final es de decadencia de los partidos tras las sucesivas crisis que afectaron al país y la de 1973 no pudieron evitarla y caen simultáneamente con el Parlamento resurgiendo en 1990 pero sin la fuerza que otrora tenían ya que el primer mandatario recobró su rol participativo, siendo solo afectado por los partidos en cuanto se limita a ejecutar sus proyectos de gobierno ${ }^{57}$.

\section{LAS CONSTITUCIONES Y SUS INSTITUCIONES EN EL ESTADO DE DERECHO}

El Estado de Derecho representa el trasfondo de las relaciones que a lo largo de la historia de Chile se han venido desarrollando y cuyas repercusiones explico a continuación.

BRAVO LIRA refiere que las constituciones coexisten desde que la constitución escrita se instauró definitivamente en 1833 bajo el gobierno de Prieto y la influencia de Portales, pero no hay que olvidar que lo que se busca es establecer el resultado de un proceso histórico que abarca desde la fundación de Chile en 1540, al comenzar el Estado su camino bajo el nombre de Reino de Chile ${ }^{58}$, ya que se sentaron las bases no solo del Estado sino también de las instituciones políticas vigentes.

Las instituciones políticas, por más que se diga lo contrario, siempre han estado presentes y lo único que ha variado es la eficacia en cuanto a cumplir las funciones que se les atribuye ya que en la sociedad chilena, en muchos $\operatorname{casos}^{59}$, han influido fundamentalmente sobre el país y, primordialmente, en el Estado de Derecho, afectado por las circunstancias políticas y sociales.

\footnotetext{
${ }^{56}$ Nogueira AlCALÁ (2005) p. 313.

${ }^{57}$ BRAVO LIRA (1996) pp. 47-51.

${ }^{58}$ BRAVO LIRA (1986a) p. 81.

${ }^{59}$ Desde su origen, a mi parecer.
} 
El Estado de Derecho nació en Chile con la constitución histórica en los siglos XVI y XVII y a ella se debe su vigencia y no a las constituciones escritas ni a las políticas partidistas, pero si contribuyen a crear contrastes dependiendo de la o las instituciones que le sostengan, justificando las fases del Estado de Derecho que propone BRAVO LIRA ${ }^{60}$, que en cada momento experimenta cambios pero no desaparece.

Al tratar las instituciones políticas propias de cada constitución es manifiesto que las que forman parte de la constitución histórica tienen una permanencia mayor que las pertenecientes a la constitución escrita, ya que estas últimas al ser formuladas en un documento que plasma sus principios no consiguen moldear a las primeras ni mucho menos imponerse, las primeras son matrices del Estado de Derecho y concurren a su formación y las segundas son complementarias y solo contribuyen a su transformación.

Las segundas son creaciones de los juristas que, intentando asemejarse a lo ocurrido en Europa, exportan estas instituciones y buscan implantarlas en una sociedad que responde a otro tipo de circunstancias pues -como se dijo- la situación de Chile fue distinta incluso al interior de América lo que hizo que hallar las soluciones en otra dirección y que estas instituciones extranjeras resultaran ser extrañas y, por lo mismo, efímeras e inestables, aunque estuviesen respaldadas constitucionalmente, y se cita como ejemplo al Parlamento, institución que no se ajusta con la demás, no conciliándose con el Estado de Derecho ${ }^{61}$.

Las instituciones propias del país se plasman en la constitución histórica y las otras solo en la medida que estén contenidas en artículos al interior de la constitución escrita ${ }^{62}$. El problema es querer ajustar ambas constituciones, compatibilizar lo antiguo con lo moderno, porque estos intentos forzosos terminan, en el peor de los casos, desbaratando el régimen de gobierno y provocando crisis que dan excusa a las Fuerzas Armadas para intervenir, e injerencia que BRAVO LIRA declara las hace institución cuyo gobierno puede equipararse a la dictadura romana, temporal y funcionando al margen de las demás instituciones ${ }^{63}$.

El Estado Judicial de Derecho tiene por finalidad la justicia, siendo a la vez elemento principal de las instituciones el Gobernador, la Real Audiencia y las Fuerzas Armadas, y con la llegada del Estado Administrativo de Derecho se incorporan la Administración y el Parlamento, los cuales buscan superponerse a las instituciones que les anteceden.

Las ideas ilustradas, a mediados del siglo XIX, influyeron en los políticos y ante la decadencia del absolutismo los movimientos independentistas comenzaron en Chile. En este contexto, el gobierno se concibe de otra manera porque se busca poner al servicio de la comunidad estos ideales y su rol no se reduce a la simple aplicación de justicia sino que también -igual que en Europa- mira a la felicidad pública, expresada en una mejora de las

\footnotetext{
${ }^{60}$ BRAVO LIRA (1996) p. 25 distingue tres periodos claramente definidos en atención a los acontecimientos históricos y aclarando que no corresponde únicamente a una cronología dentro de la Historia de Chile, sino que responde además a una concatenación institucional. Estos son el Estado Judicial (1541-1760), el Estado Administrativo (1760-1860) y el Estado Legalista (1860 hasta el presente).

${ }^{61}$ BRAVo LiRA (1996) p. 64.

${ }^{62}$ BRAVo LIRA (1996) p. 33.

${ }^{63}$ Bravo LiRa (1996) p. 183.
} 
condiciones sociales en que vive la gente. El monarca debe poner a disposición los medios para que se realice. Ese es su fin ${ }^{64}$.

Son estos los fundamentos que aduce BRAVO LIRA para asimilar este periodo al Estado Administrativo de Derecho, siendo el Presidente la figura que adquiere mayor preponderancia frente a las demás instituciones y un Estado de Derecho debilitado por las crisis anteriores a $1830^{65}$, entrando en juego la influencia de Portales ${ }^{66}$, cuya obra significó el regreso de la monocracia tras la anarquía experimentada con anterioridad. Es llamada la República Ilustrada y fue la respuesta que se dio al vacío que dejó la Monarquía Ilustrada ${ }^{67}$.

Aclaro que este periodo al que se hace mención no se corresponde con la adopción del Estado de Derecho en Chile. Antes de Portales existía Estado de Derecho, solo que hasta entonces no había sido influenciado por la Ilustración, llevándose a la práctica varios años después, en donde el influyente ministro es actor importante.

Durante la Anarquía, que va desde la caída de O`Higgins hasta la batalla de Lircay ${ }^{68}$, dominó el cesarismo, con gobiernos y ensayos constitucionales entre 1823 y 1831 que provocaron desconcierto y desorden, y al asumir el poder José Joaquín Prieto, similar al sistema que instauraron los emperadores Antoninos, lo característico fue que el gobernante de turno elegía a su sucesor, siendo Manuel Bulnes escogido por Prieto y Manuel Montt por Bulnes.

En palabras de EDWARDS VIVES, el ideal portaliano es propio y no concebido por sus contemporáneos $^{69}$ y restaura la existencia de un poder fuerte y duradero y un sentimiento consistente en el respeto que se siente hacia la autoridad, hacia el poder legítimo. En términos simples, Portales recuperó la figura del monarca absoluto, encarnado en el Presidente, pero solo en tanto autoridad no en cuanto poder ${ }^{70}$ dado que no sentía particular aprecio por el constitucionalismo y por eso manifestó «Ninguna obra de esta clase $e^{71}$ es absolutamente buena ni absolutamente mala, pero ni la mejor ni ninguna servirá para nada cuando esté descompuesto el principal resorte de la maquina».

La intención de Portales era despertar el respeto que se siente solo por las instituciones consagradas, todo para superar el desorden institucional previo ${ }^{72}$, y fue un hombre constructivo y revolucionario que llegó a la cumbre de su poder y éxito en septiembre de 1831, cimentando el que sería un gobierno serio y estable, vencedor sobre la oposición y

\footnotetext{
${ }^{64}$ BRAVO LiRA (1996) pp. 140-141.

${ }^{65}$ BRAVO LiRA (1996) pp. 203-204.

${ }^{66}$ BRAVO LIRA (1992) p. 171 y (1992-1993) pp. 322-323 asevera que «Su actuación [la de Diego Portales] presenta dos vertientes complementarias. Por un lado, logra acabar con la anarquía y, por el otro, consolidar las instituciones. Esto último supone nada menos que dar una nueva forma, constitucional, al ideal ilustrado de gobierno. Forja así un Estado constitucional, católico y nacional, que es una suerte de república ilustrada, capaz de llenar el vacío dejado por la monarquía ilustrada».

${ }^{67}$ BRAVO LIRA (1996) pp. 291-293.

${ }^{68}$ CAMPOS HARRIET (1999) p. 136.

${ }^{69}$ EDWARDS VIVES (2012) p. 60.

${ }^{70}$ EdWARdS Vives (2012) p. 61.

${ }^{71}$ Se refiere a las constituciones.

${ }^{72}$ EdWARDS VIVES (2012) p. 65.
} 
dominante sobre la aristocracia, quienes no veían con buenos ojos al ministro pero, dada las circunstancias, no les quedó más salida que agachar la cabeza.

Portales buscó el equilibrio y la estabilización del poder, apoyando su creación en las antiguas fuerzas tradicionales, las instituciones de la constitución histórica, rotas por la revolución independentista y por los motines anarquistas ${ }^{73}$. En este sentido, añade EDWARDS VIVES, Portales, si bien no era partidario del constitucionalismo, busca amoldarse a la constitución histórica sin sacrificar sus instituciones ${ }^{74}$, reafirmando la situación vivida en el pasado con Carrera y O’Higgins, de los que el mentado reivindicó la antigua autoridad y la depositó en el Presidente, figura que encarna el gobierno, no obedeciendo a la persona sino a la institución que representa. Señala CAMPOS HARRIET, la gente le obedeció «con el alma y de hecho» ${ }^{75}$ porque en vez de un rey se reinstaura la majestad real pero como un Presidente constitucional, una autoridad impersonal. Introdujo también el Parlamento, institución desconocida en ese instante, cuyo fin es velar por que la gestión del gobierno sea legal ${ }^{76}$.

La crisis del Estado Administrativo se resolvió exaltando al Presidente y la obligación de velar por el correcto funcionamiento de las demás instituciones pero con la aparición de los Partidos Políticos y su influencia sobre el Parlamento ${ }^{77}$, utilizado para demoler a las instituciones fundamentales, lo que duró desde 1860 hasta 1920, se vuelven a generar tensiones entra ambas constituciones, dando origen al Estado Legalista de Derecho.

El militarismo en 1920 responde a las fricciones que venían dándose entre las instituciones de ambos bandos, en particular a la hegemonía de los partidos y la clase política, al ser ellos los árbitros de la constitución escrita, de su modificación y de su aplicación ${ }^{78}$, crisis que se repitieron y originaron intervenciones militares en 1925 y 1973.

La intervención castrense restaura la monocracia denotando Partidos Políticos en visible decadencia y las Fuerzas Armadas, institución no sujeta a ellos ${ }^{79}$, asumen un rol protagónico de salvaguarda del Estado de Derecho y de la constitución histórica. En opinión de BRAVO LIRA, las instituciones fundamentales no solamente se recuperan sino que se fortalecen ${ }^{80}$, ya que estas pertenecen a la esfera del Estado mientras que los partidos a la esfera mudable y su caída no se debió a una incomprensión de las demás instituciones fundamentales sino a ser inoperantes al interior del Estado de Derecho.

\footnotetext{
${ }^{73}$ CAMPOS HARRIET (1999) p. 158.

${ }^{74}$ EDWARDS VIVES (2012) pp. 99-100.

${ }^{75}$ CAMPOS HARRIET (1999) p. 160.

${ }^{76}$ BRAVO LIRA (1986a) p. 192.

77 Para BRAVO LIRA (1986b) p. 27 «[...] el régimen constitucional de gobierno que en Chile se había implantado sobre la base de la dualidad presidente-Parlamento fue ampliado para acoger también a esta institución [los Partidos Políticos] surgida más tardíamente. Su introducción en 1925 dio un sello oficial a la trilogía presidente-partidos-Parlamento que existía en la práctica desde 1874 y que persistió hasta 1973».

${ }^{78}$ BRAVO LIRA (1986a) p. 219.

${ }^{79}$ BRAVO LIRA (1996) p. 237.

${ }^{80}$ BRAVO LiRA (1996) p. 205.
} 
Carlos Ibáñez del Campo, quien dio un golpe de Estado el 23 de enero de 1925, asume, elección mediante, la presidencia el 21 de junio de 1927 y recupera las instituciones fundamentales pero estas no quedan libres del partidismo y se regresa al gobierno de partidos y se deterioran y son desplazadas nuevamente. La existencia de las oligarquías partidistas entre 1933 y 1973, junto al Presidente, se hacen un lugar frente a las demás instituciones.

La designación de miembros de las Fuerzas Armadas como Ministros de Estados en el gobierno del Presidente Salvador Allende, ante la presión ejercida sobre las instituciones fundamentales en 1970, es un factor que pudo contribuir al quiebre del Estado de Derecho, y lo cierto es que después del 11 de septiembre de 1973 la constitución histórica y sus instituciones se fortalecen desapareciendo, igual que en 1924, el gobierno de partido el que, posterior a 1990, no es de afirmar que se restableció porque la Constitución de 1980 en vigor consagra un régimen presidencial reforzado o ultra-presidencial ${ }^{81}$.

\section{CONCLUSIONES}

La Historia no es un estudio de hechos aislados sino un análisis de una cadena de grandes procesos que responden a coyunturas diversas los cuales crean un eslabón que jamás termina. La Historia es cíclica, los sucesos se repiten, y en la tesis presentada se puede comprobar con el auge y caída de las instituciones políticas, las constituciones y el mismísimo Estado de Derecho, concepto clave de nuestra cultura jurídica, conservando su estructura básica pero alterada por las instituciones con las que le corresponde relacionarse en determinado periodo.

El enfoque aquí, en el que las instituciones políticas representan un papel crucial en el desarrollo de los hechos, y su lugar dentro de las constituciones histórica y escrita, tiene por propósito desvelar los vínculos que se dan en uno y otro sentido a objeto de contemplar el proceso de forma secuencial y marcado por las crisis experimentadas, motivando a las instituciones a modificar sus funciones y adoptar roles, en algunos casos, diferentes al que originalmente tenían.

Se advierte que desde un comienzo la constitución escrita regula las instituciones vigentes de la constitución histórica e incorpora otras ajenas y desconocidas ${ }^{82}$ y ello no implica que las redactadas sean malas pues constituyen un aporte a la estabilidad del Estado y sus instituciones si guardan correlación con ellas, solo que si su articulado se torna frágil y sin fijeza, a contrario sensu, la constitución histórica y sus instituciones pasan a un primer plano, cual aconteció con los Partidos Políticos una vez derribados por el militarismo.

Actualmente el Estado legalista de Derecho cumple una función activa, protege los derechos esenciales de las personas y promueve y asegura la vigencia de los valores necesarios para la convivencia en sociedad ${ }^{83}$ y ya va quedando atrás permitiendo un Estado subsidiario de Derecho que libera y renueva a las instituciones de la constitución histórica,

${ }^{81}$ Vid. por todos Godoy ARCAYA (2009).

${ }^{82}$ BRAVO LIRA (1986a) p. 261.

${ }^{83}$ ViVANCO MARTíneZ (2001) p. 235. 
anteriores y por sobre todo superiores a las pertenecientes a la escrita, y esto porque el Estado legalista alcanzó estabilidad. De ningún modo el régimen político debe imponerse y siempre ha de procurarse que se cimente en armonía con las instituciones vigentes y no por acuerdos de oligarquías imperantes cual así hicieron los partidos.

Dada la acción modernizadora de los gobiernos y la inclusión de instituciones como el Parlamento y los Partidos Políticos, colisionaron el país legal y el real de las constituciones, o sea, un estrato antiguo y arraigado y otro reciente y superpuesto al anterior provocando un desgaste en el Estado de Derecho que en ocasiones extrema lo legal construyendo una fachada de institucionalidad antes que una verdadera imagen de orden. Las constituciones escritas no dejan huella porque el papel aguanta mucho pero no los pueblos y países, lo que no acontece con las instituciones de la constitución escrita ya que, desde su arraigo en la mismísima fundación, responden a la cultura e idiosincrasia de sus habitantes y, más aún, el Estado de Derecho debe su existencia a ellas, su vigencia y continuación. La victoria es de la constitución histórica al no dejarse modelar por la escrita.

Las constituciones escritas son expresión de la revisión, inspiradas por los ideales ilustrados y cuyo fin es reemplazar las instituciones fundamentales por una carta perfecta, la misma que provoca la disociación entre su contraparte histórica y sus instituciones. El pueblo y las instituciones se resisten ser estructurados por los textos constitucionales, es decir, existe un permanente abismo entre ambas visiones.

La historia de Chile y el Estado de Derecho son temas apasionantes y no solo porque los hechos que se narran y sus participantes siguen despertando la curiosidad y el interés de quienes leen acerca de ellos sino también porque son observables desde una nueva perspectiva, dejando entrar al Derecho y la Filosofía como elementos que pueden determinar las consecuencias de estos procesos históricos cuyo punto final el devenir inexorablemente demuestra que es ilusorio.

\section{BIBLIOGRAFÍA CITADA}

ARISTÓTELES (2007): Política (Traducción, introducción y notas Manuela García Valdés, Barcelona, Editorial Gredos).

BARrientos Grandon, Javier (2000): La Real Audiencia de Santiago de Chile (16051817): $\quad L a$ institución $y$ sus hombres. Disponible en: http://www.larramendi.es/i18n/consulta/registro.cmd?id=1121, fecha de consulta: 7 de junio de 2019.

Bravo LiRA, Bernardino (1986a): Historia de las Instituciones Políticas de Chile e Hispanoamérica (Santiago de Chile, Editorial Andrés Bello).

(1986b): Régimen de gobierno y partidos políticos en Chile. 1924-1973 (Santiago de Chile, Editorial Jurídica de Chile).

(1992): El absolutismo ilustrado en Hispanoamérica: Chile (1760-1860) de Carlos III a Portales y Montt (Santiago de Chile, Editorial Universitaria). 
, (1992-1993): "El primer constitucionalismo en Chile (1811-1861)", Revista de Estudios Histórico-Jurídicos, № 15, pp. 303-331.

(1994-1995): "Presidente y Gobierno en Chile: De la monarquía a la monocracia", Revista Chilena de Historia y Geografía, No 161, pp. 147-176.

(1996): El Estado de Derecho en Chile: Por la razón o la fuerza (Santiago de Chile, Ediciones Universidad Católica de Chile).

CAmpos Harriet, Fernando (1999): Historia Constitucional de Chile: Las instituciones políticas y sociales ( $7^{\mathrm{a}}$ ed., Santiago de Chile, Editorial Jurídica de Chile).

Cea Egaña, José Luis (2008): Derecho Constitucional Chileno. T. I (2 $2^{\mathrm{a}}$ ed., Santiago de Chile, Ediciones Universidad Católica de Chile).

CICERÓN (1984): Sobre la República (Traducción, introducción, apéndice y notas Álvaro D’Ors, Madrid, Editorial Gredos).

EDWARDS VIVES, Alberto (2012): La fronda aristocrática en Chile (17 a ed., Santiago de Chile, Editorial Universitaria).

EYZAGUIRRE GUTIÉRREZ, Jaime (1967): Historia de las instituciones políticas y sociales de Chile (Santiago de Chile, Editorial Universitaria).

FríAs VAlEnZUEla, Francisco (2007): Manual de Historia de Chile (25 a ed., Santiago de Chile, Editorial Zig-Zag).

GODOY ARCAYA, Óscar (2003): "Parlamento, presidencialismo y democracia protegida", Rev. cienc. polít. (Santiago), vol. 23, $\mathrm{N}^{\circ}$ 2, pp. 7-42. Disponible en: https://scielo.conicyt.cl/pdf/revcipol/v23n2/art02.pdf, fecha de consulta: 5 de junio de 2019.

GUZMÁn BRITO, Alejandro (2002): "El vocabulario histórico para la idea de constitución política”, Revista de Estudios Históricos-Jurídicos, N² 24, pp. 267-313.

Kelsen, Hans (2009): Teoría Pura del Derecho (Trad. Moisés Nilve, Buenos Aires, Eudeba).

Montesquieu (2003): Del Espíritu de las Leyes (Trad. Enrique Tierno Galván, Mercedes Blázquez y Pedro de Vega, Madrid, Alianza Editorial).

Nogueira Alcalá, Humberto y Cumplido CerecedA, Francisco (2001): Instituciones Políticas y Teoría Constitucional. T. I (Talca, Editorial Universidad de Talca).

Nogueira AlcalÁ, Humberto (2005): "El rol de los partidos políticos en las Constituciones de América Latina en la alborada del siglo XXI", Revista de Estudios Constitucionales, vol. 3, № 2, pp. 309-360. 
Polibio (1981): Historias. Libros V-XV (Traducción y notas de Manuel Balasch Recort, Madrid, Editorial Gredos).

Verdugo Marinkovic, Mario y García Barzelatto, Ana María (2010): Manual de Derecho Político. Instituciones Políticas. T. I (4⿳亠丷厂 ed., Santiago de Chile, Editorial Jurídica de Chile).

, (2011): Manual de Derecho Político. Las Fuerzas Políticas y los Regímenes Políticos. T. II (Santiago de Chile, Editorial Jurídica de Chile).

Villalobos Rivera, Sergio et al. (2006): Historia de Chile (Santiago de Chile, Editorial Universitaria).

Vivanco MARTíneZ, Ángela (2001): Curso de Derecho Constitucional. Bases conceptuales y doctrinarias del Derecho Constitucional. T. I ( $2^{\mathrm{a}}$ ed., Santiago de Chile, Ediciones Universidad Católica de Chile). 